ISSN 1112-9867

Available online at

http://www.jfas.info

\title{
EXPLORING THE CYCLIC LOADS CONDITIONS ON BEHAVIOR OF MODIFIED CONNECTOR PLATE OF STEEL FRAME CBF
}

\author{
M. Fathi $*^{1}$, H. R. Amiri ${ }^{2}$, H. A. Rahimi ${ }^{3}$ \\ ${ }^{1}$ Department of Civil Engineering, Yazd Branch, Islamic Azad University, Yazd, Iran \\ ${ }^{2}$ Department of Civil Engineering, Yazd Branch, Islamic Azad University, Yazd, Iran \\ ${ }^{3}$ Department of Civil Engineering, Yazd University, Yazd, Iran
}

Published online: 11 June 2016

\begin{abstract}
One of the disadvantages of convergent steel frames, is loss of strength of this brace under cyclic loading. Studies in recent years show that in the event of changes in raw form Gusset plate sheet, and the creation of suitable geometry and as well as the type of consumable materials used for it; initial conditions can be provided to increase ductility and resulting increased in energy dissipation. Braces as earthquake resistant elements in different ways are applied to cope with lateral forces of earthquake. One important element of these systems is Gusset plate sheets which plays an important role in the transmission of lateral forces. The behavior of these members can be investigated under tensile and comprehensive loading uniform. The pressure behavior due to its complexity and more failure modes have been less studied.
\end{abstract}

Author Correspondence, e-mail: mah_13772000@yahoo.com

doi: http://dx.doi.org/10.4314/jfas.8vi2s.32 
According to investigation conducted, the desired failure mode of Gusset plates under the pressure is surrendered. However, in most cases the connection sheet under pressure surrenders to bucking load and cannot be lodged with the brittle failure and the result does not show good ductility. In order to change the dominant failure mode and delaying bucking of stiffeners Gusset plate the stiffness and changes in their geometry are used. In this study, using Abacus software to evaluate the impact of changes in plate Gusset and the stiffeners edge of sheets have been examined. The results obtained indicate that the postponement of bucking curves in the modified connector plate and thereby improve behavior of connector plates under the pressure forces and also represents the high configurability of modified connector sheets.

Keywords: Gusset Plate, Plasticity, Buckling, Brittle Failure.

\section{INTRODUCTION}

The disadvantage of steel bracing convergent is the result of difference between the pressure and elasticity capacity in braces and decline in the strength of braces under comprehensive loading. Therefore, due to low deformation plasticity, they have instability capacity and more buckling. Hence, a lot of researches have done to improve the braces to achieve the ideal behavior. In connection of Gusset plate, with analysis of cycle tensile and pressure forces can address to model tensile and pressure loading uniformly. Under the tension the prevailing mode is Gusset plate and the attachment sheet without any buckling start to waste energy. But connection sheet under the pressure forces have different comprehensive modes that it causes damage to the energy dissipation of Gusset plate. Therefore, a parametric study of the behavior under the connecting sheets under the cyclic loads was done which is described below. The first part is the history of researches on the connection sheets has been reviewed and the summary of the results of work is provided. As well as the modeling and validation of a numerical model based on the most recent research is expressed. Finally, a parametric study is done to investigate the formability of connection sheet. 


\section{The Connection Sheet Buckling Criteria}

So far, few studies have been done to investigate the local and overall buckling of the connection sheets. Each of these studies has provided a measure to prevent the buckling of connection steel sheets of CBF.

Brown [1] has done one of the studies in the field of edge buckling of Gusset plate and the use of edge stiffeners in different thickness of Gusset plate, in which the results of compression and buckling analysis of Gusset plate is provided. In this research, equation (1) has been presented to prevent buckling edge Gusset plate before the submission:

$$
\frac{\mathrm{Lfg}}{\tau}=0.83 \sqrt{\frac{E}{F y}}
$$

Where $\mathrm{E}$ is the modulus of elasticity, $\mathrm{t}$ Gusset plate thickness, FY yield Gusset plates tension and Lfg the length of free edge of Gusset plate. The above equation is used for elasticity of buckling of free edge of Gusset plate under monotone comprehensive loads.

For Gusset plate under the tensile and comprehensive loads with large cycle even when the connection is established, again the edge buckling in bracing connection occurs. Threshold principle and colleagues [2] in 1991 equation 2 are provided to prevent edge buckling of bracing connection sheet. The main issue for them was connected buckling sheets.

$$
\frac{\mathrm{Lfg}}{\tau}=0.75 \sqrt{\frac{E}{F y}}
$$

\section{Research Background and Necessity of This Research}

$\mathrm{Hu}$ and Cheng were carried out an experimental and numerical study on the behavior of brace connecting sheets under monotonic compressive loads [3]. Their experimental program was concentrated on thickness, geometry, boundary conditions and eccentricity. Cheng and Ho's work showed that by modifying the brace connection sheets, buckling of thin plates happened at lower loads, which is obtained by Vitmor method. As well as, for the promotion of compressive behavior of connecting sheets and use of energy dissipation, the use of hard edge is good.

Study on the hard edge has done for the first time by Williams and Richard [4] on the diagonal braces. Then after Cheng [5] the study on the hard edge was continued widely. Cheng research 
showed that the hard edge will improve the absorption of energy by Gussset plate. Walbridge et al [6] have done the numerical study on the connection behavior under cyclic loads with the construction of a number of numerical examples in ABAQUS software. They validate their models for monotonic loading used the results of tests by Yum and Cheng [7] and for cyclic loading modes used the results of Rabinovich and Cheng [8]. In this study, factors such as thickness, geometry of sheets, the frame, the non-linear behavior of materials, initial defect parts, screw slip boundary conditions were investigated. As well as, for exploring the Ribinovitch and Cheng theory on how strong bracing design, weak sheets have been presented in their models. Based on the results, they provided the suggestions on how to model the behavior of materials, screws and initial defects on connection sheets. Studies showed that a curve of force- deformation in the mode of monotonic loading-hysteresis curves cover the same subjects under the cyclic loads. According to Walbridge et al., when the connection sheet buckles sooner, the energy dissipation is much better. In this study, a modified connector plate with stiffeners and low resistance steel independently with Gusset plate were compared simply. Modified connection sheets before buckling like fuses can cause the absorption and energy dissipation and can prevent the development of structural damages to other organs.

\section{Modeling The Finite Elements of Gusset Plate}

\subsection{Introducing Elements and Used Criteria}

For modeling different components of connection sheets of Gusset plate including bar, column, organ and stiffness edge like figure (1) in the ABAQUS software was used the C3D8I elements from three-dimensional elements of eight knots. This element is able to show all attempts, strain hardening, large deformations (the effect of buckling) and elasticity in nonlinear analysis. Also, the direction of buckling applied to the model used the primary defect in the edge of connection sheets. 


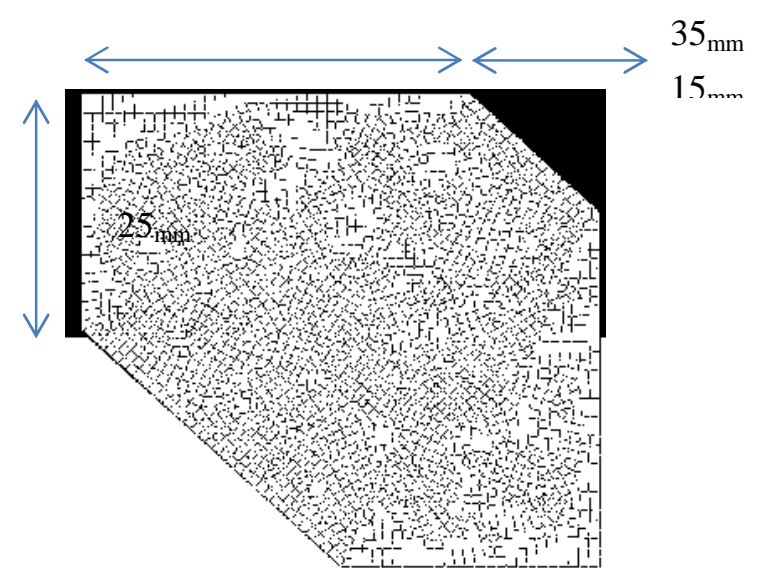

Fig.1. The characteristics of modified Gusset plate

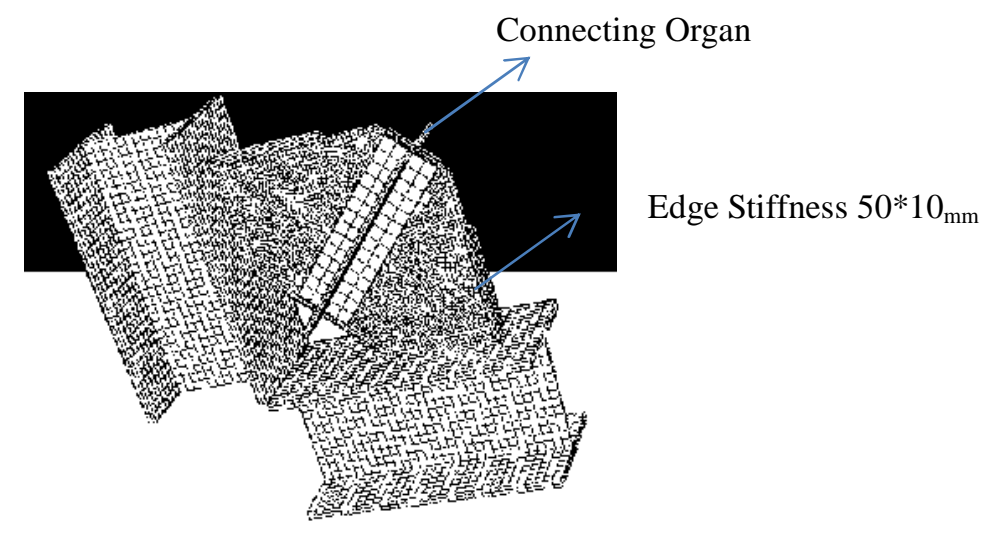

Fig.2. The finite elements of system model

\subsection{Used Materials}

Steel used for beams, columns, structural steel ST37 and steel used for Gusset plate sheets and steel ST37 and steel LYS have been used with different models. Specification and stress-strain values are shown in table 1 . 
Table 1. Specification of usable materials

\begin{tabular}{|c|c|c|c|c|c|}
\hline $\begin{array}{c}\text { Type of } \\
\text { Steel }\end{array}$ & $\begin{array}{c}\text { Strain } \\
\text { failure }\end{array}$ & $\begin{array}{c}\text { Yield } \\
\text { Strain }\end{array}$ & $\begin{array}{c}\text { Ultimate } \\
\text { Stress }\left(\mathrm{kg} / \mathrm{cm}^{2}\right)\end{array}$ & $\begin{array}{c}\text { Yield } \\
\text { Stress } \\
\left(\mathrm{kg} / \mathrm{cm}^{2}\right)\end{array}$ & $\begin{array}{c}\text { Module } \\
\text { Elasticity } \\
\left(\mathrm{kg} / \mathrm{cm}^{2}\right)\end{array}$ \\
\hline ST37 & 0.2 & 0.0012 & 3700 & 2400 & 2000000 \\
\hline LYS & 0.4 & 0.00062 & 3000 & 1200 & 1950000 \\
\hline
\end{tabular}

The behavior of material have been considered as non-linear and in all models the measure of Von Misses and Kinematic hardening law have been used to evaluate the results.

\subsection{Uploading}

Uploading has been carried out as a shift to the junction of bracing as the organ. Because the uploading to shift is done in the Abaqus software the integration is better than force. Also, in the most regulations in the world, the uploading patterns to shift is used for forming structural members. In this study, uploading is done by shifting. Uploading has been done to the charge and cyclic uploading. In order to include the cyclical nature of dynamic loads and reducing calculation errors, the procedure ATC-24 has been used. Figure 3 shows the uploading diagram.

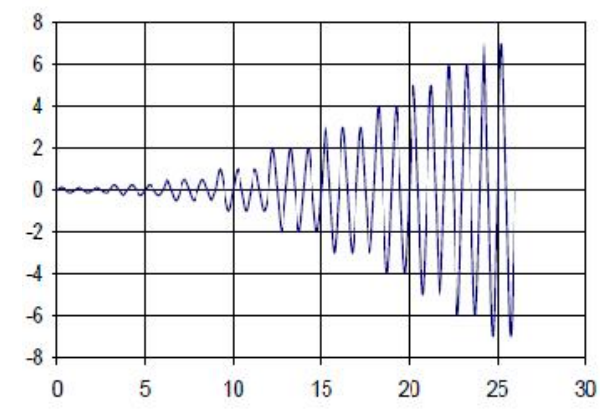

Fig.3. Cycle number - Act displacement curve

For assessing of buckling and dropping of resistance, and also to specify the amount of energy loss, and obtain attenuation in the nonlinear behavior of the system and the connection uploading of samples we used the cyclic analysis.

\subsection{Boundary conditions}

In all models, as shown in figure 4, the end of beam and column was clamped. 


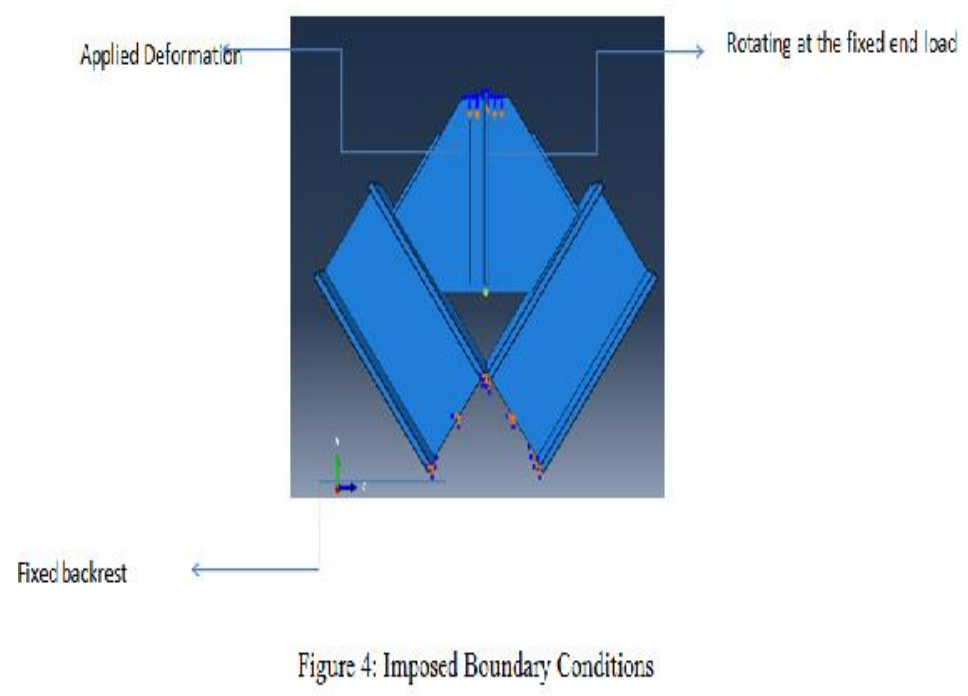

Fig.4. Imposed Boundary Conditions

\section{Verifying by using the test results of Yum and Cheng}

In this study for the verification of software performance and modeling, the results of laboratory models of Yum and Cheng are used [10]. According to figure 5, and the results are presented in table2, the results of analysis had a good match with the work of Yum and Cheng.

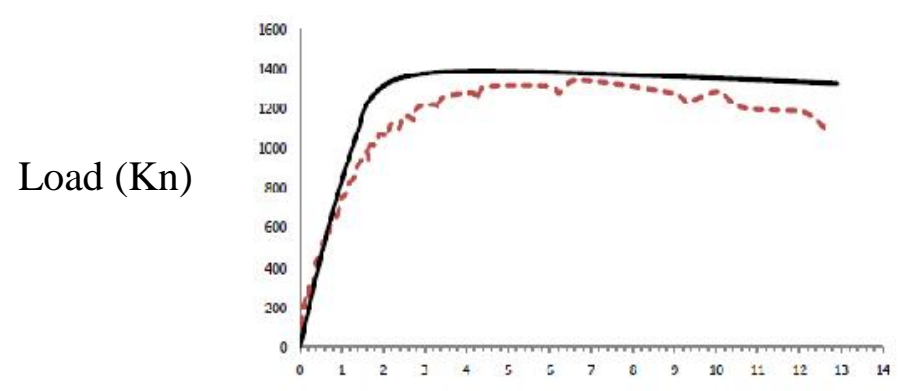

Fig.5. Verification of software model with experimental model 
Table 2. The comparison of verification results

\begin{tabular}{||c|c|c|c|c||}
\hline \hline The & $\begin{array}{c}\text { Bracing } \\
\text { Angle } \\
\text { connection } \\
\text { thickness }\end{array}$ & $\begin{array}{c}\text { Experimental } \\
\text { Horizon } \\
(\mathrm{mm})\end{array}$ & $\begin{array}{c}\text { Software } \\
(\mathrm{kn})\end{array}$ & $\begin{array}{c}\text { Percentage } \\
\text { of } \\
\text { Difference }\end{array}$ \\
\hline 9.8 & 30 & 1356 & 1420 & $\begin{array}{c}\text { Compressive } \\
\text { Strength }\end{array}$ \\
\hline \hline
\end{tabular}

\section{Specification of studied models}

Models with and without hard edge have been studied with the change in the geometry of different steel in accordance with the dimensional given in table 3. In this study, one of the models studied with 12 foramen ovale with dimensions of 125 x $25 \mathrm{~mm}$ with hardener edge.

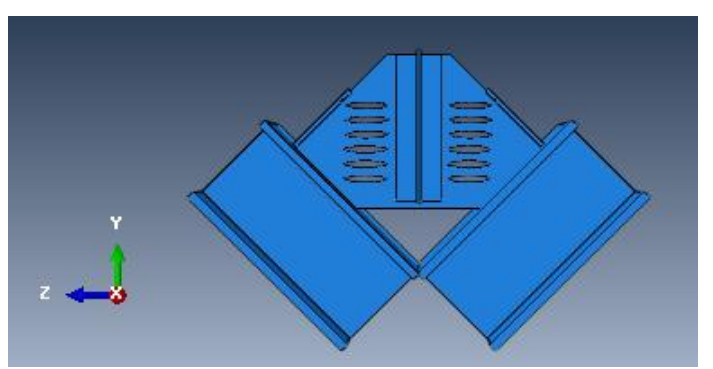

Fig.6. Changed Gusset plate GP4 with 12 foramen ovale 
Table 3. Specification of Models

\begin{tabular}{|c|c|c|c|c|c|c|c|c|}
\hline Row & $\begin{array}{l}\text { Model } \\
\text { Name }\end{array}$ & $\begin{array}{c}\text { Sheet } \\
\text { Thickness } \\
\text { (mm) }\end{array}$ & $\begin{array}{l}\text { The } \\
\text { angle of } \\
\text { Bracing } \\
\text { with } \\
\text { Horizon }\end{array}$ & $\begin{array}{l}\text { Section } \\
\text { beams } \\
\text { and } \\
\text { Column }\end{array}$ & Organ & $\begin{array}{c}\text { Type } \\
\text { of } \\
\text { Steel }\end{array}$ & $\begin{array}{c}\text { Hardener } \\
\text { edge } \\
\text { (mm) }\end{array}$ & $\begin{array}{l}\text { Geometry } \\
\text { Changes }\end{array}$ \\
\hline 1 & GP1 & 10 & 45 & IPB300 & 1/2INP300 & ST37 & ----- & Not have \\
\hline 2 & GP2 & 10 & 45 & IPB300 & $1 / 2 \mathrm{INP} 300$ & LYS & $50 * 10$ & Not Have \\
\hline 3 & GP3 & 10 & 45 & IPB300 & $1 / 2 \mathrm{INP} 300$ & LYS & $50 * 10$ & have \\
\hline
\end{tabular}

\section{Checking Results}

\section{The comparison of simple Gusset plate with Gusset plate with hardening steel edge}

\section{and steel LYS}

Simple Gusset plate is like the recovery Gusset plate with this difference that the bracing angle with horizon is 45 degrees and the modified Gusset plate is with hardening edge with a hard edge $50 \mathrm{~mm}$ and thickness of $10 \mathrm{~mm}$. It is noteworthy that all conditions are the same for models and the only difference is in the lack of hard edge and not having hard edge and the changes in geometry and useable materials in Gusset plate. By comparing the buckling mode after loading and analysis of models in figure 6 and 7 we conclude that unlike simple Gusset plate which have buckling edge. According to table 3, determine the form of factor of samples show that the modified Gusset plates have been changed more simple than simple Gusset plate. Here, for the calculation of plasticity, the maximum amount of cyclic shift power - system displacement divide on current displacement and we obtain plasticity index. 


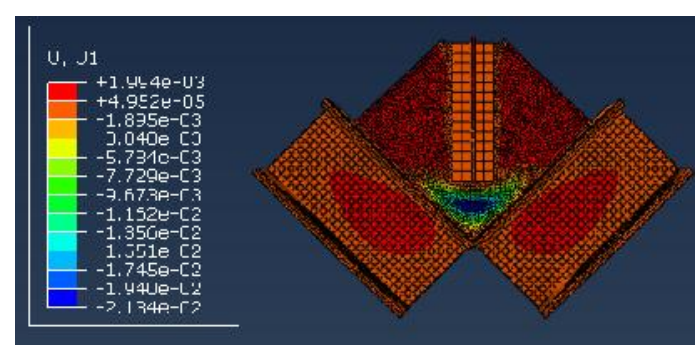

Fig.7. Buckling out of plane models with steel stiffeners and LYS

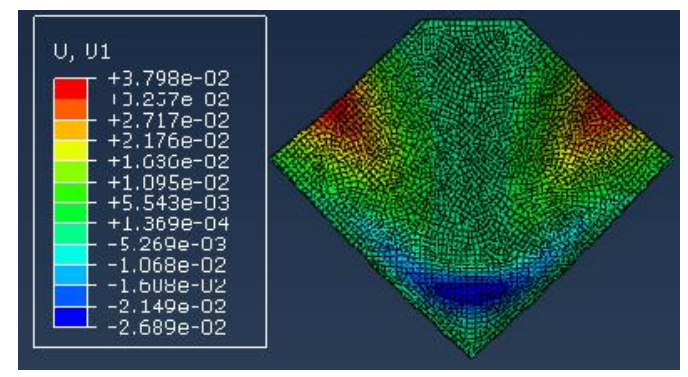

Fig.8. The location and amount of buckling out of plane prototype

Table 4. Determine the form factors of samples

\begin{tabular}{||c|c|c|c||}
\hline \hline $\begin{array}{c}\text { Name } \\
\text { of } \\
\text { Model }\end{array}$ & $\begin{array}{c}\text { The } \\
\text { maximum } \\
\text { displacement } \\
(\mathrm{mm})\end{array}$ & $\begin{array}{c}\text { The } \\
\text { surrender of } \\
\text { displacement } \\
(\mathrm{mm})\end{array}$ & $\begin{array}{c}\text { Form } \\
\text { index }\end{array}$ \\
\hline GP1 & 8 & 1.2 & 6.66 \\
\hline GP2 & 17 & 2.05 & 9.2 \\
\hline \hline
\end{tabular}

As shown in figure 8, it can be seen that Hysteresis curve of modified Gusset plates has flattened circles and are regular. It represents the ability to absorb more energy than simple Gusset plates. It also modified model shows the same behavior in tension and pressure. This represents an increase of plasticity in the pressure loading on frame system with the coaxial steel bracing. 
(A)
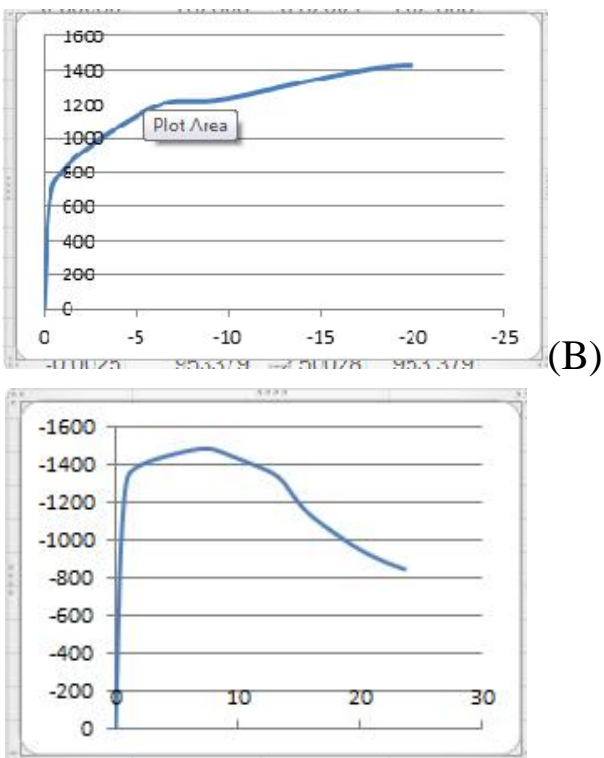

Fig.9. Hardening effect on power displacement curves (a) GP2 Model and (b) GP1 Model

\section{The comparison of simple Gusset plates and modified Gusset plates with hard steel edge and steel LYS}

In the corresponding member of the models for loads less than the yield stress, the answer is quite elastic and reversible. In one cycle of loading and unloading these is not any energy waste. But when stress exceeds the yield stress, the material has entered the deformation behavior which is irreversible. In this case, one cycle of loading and unloading energy will waste which much of this energy is converted to heat. As shown in figure $(9,10)$ the amount of plastic hinge in modified Gusset plates is more than simple Gusset plates. This represents the good behavior for wasting of modified Gusset plate.

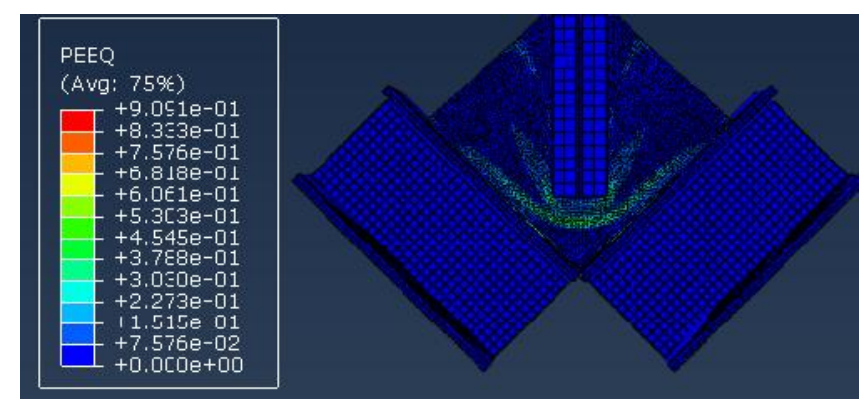

Fig.10. The location and amount of formed plastic hinge in original model 


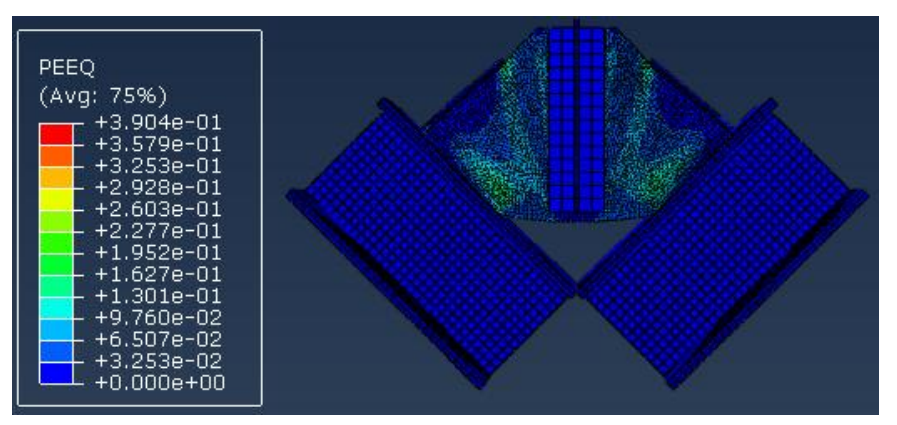

Fig.11. The location of plastic hinge in the model with stiffeners and low resistance steel

Also according to the figure 11, comparing the analytical results of models leads to this that Hysteresis curve of Modified Gusset plates have reel and regular spindle. It represents the ability to absorb more energy than simple Gusset plate. Also the modified model shows the same behavior in pull and push situation. This shows that an increase of plasticity in the loading pressure on frame systems with steel coaxial bracing.

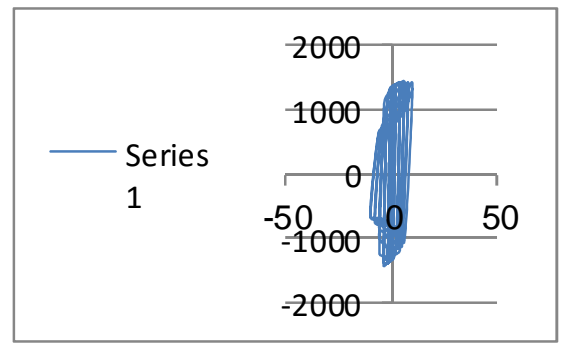

A)

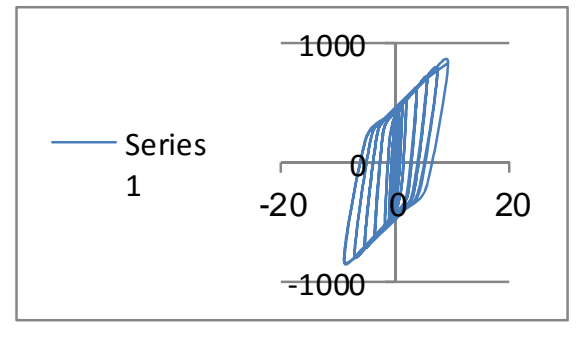

B)

Fig.12. Gusset plate deformation effect on the Hysteresis curve (a) GP1 model and (b) GP3 model

\section{CONCLUSION}

In aim of this article was the exploring the pressure behavior on connector sheet and by changing the bracing connector sheet lead to eliminate edge bracing and convert to total bracing. Studies show that edge stiffeners will increase loading and forming the Gusset plate. The conducted analysis studies show that:

1. Increase forming is possible by modified Gusset plate.

2. The capacity of modified Gusset plate is related to the materials and the changes in the geometry, designing for variety of loadings is possible and can be designed as bracing and connector sheets to ensure that a lack of bracing buckling. 
3. Change the mode of failure from edge bracing to state bracing according to threshold definition, will improve ductility of the model.

4. Yield stress of steel LYS is less than steel ST37, while modulus of elasticity of both steel is approximately equal to each other, so Gusset plate sheets with steel LYS before the Gusset plate sheets and bracing start buckling will begin to surrender and energy depreciation. It can be use as a fuse in the structure.

5. Gusset plate sheets have little movement out of the screen that it increases the ability of the organ.

6. Change the Gusset plates is simple in terms of implementation and does not need to experts and expensive materials and technology and there is the possibility of making and implementing in Iran.

\section{REFERENCES}

[1] Bron, V.L.S., (1998). "Stability of Gusset Connection in Steel Structures", Doctoral Dissertation, Depart. Of Civil Engrg, Univ. of Delaware.

[2] Astaneh -Asl, A., Bolourchi, S., and Ahmadi, M. (1991)." Damege to equipment and non-structural elements during June 21.1990 Iran Earthquake. "Proceedings, ATC Conf., Applied Technology Council.

[3] Walbridge,S.S.,Grondin,G.Y. and Cheng, J.J.R. (1998), An analysis of the cyclic behavior of steel gusset plate connections, Structural Engineering Report No. 225 , Department of Civil and Environmental Engineering, University of Alberta ,Edmonton , Alta,.

[4] Williams, G. C and Richard. R. M. (1996). "Analysis and design of large diagonal bracing connections.” Structural - Enginerring -Review. V 8 n1 Feb 1996, P 1-27

[5] Rabinovitch, J. S .and cheng, J. J.R. (1993). "Cyclic Behavior of Steel Gusset Plate Connections" Report No. 191, University of Alberta.

[6] Walbridge, S.S., Grondin, G.Y., and Cheng, J.J.R. (1998). An analysis of the cyclic behavior of steel gusset plate connections. Department of Civil and Environmental 
Engineering, University of Alberta, Edmonton, Alta. Structural Engineering Report no. 225 .

[7] Yam, M.C.H., and Cheng, J.J.R. (1993). Experimental investigation of the compressive behavior of gusset plate connections. Department of Civil and Environmental Engineering, University of Alberta, Edmonton, Alta. Structural Engineering Report no. 194.

[8] Rabinovitch, J.S., and Cheng, J.J.R. (1993). Cyclic behavior of steel gusset plate connections. Department of Civil and Environmental Engineering, University of Alberta, Edmonton, Alta. Structural Engineering Report no .191

[9] Applied Technology council (1992) "Guidelines for seismic testing of components of steel structures". Report ATC-24

[10] Yam, M.C.H. and Cheng, J.J.R. (2001), "Behavior and design of gusset plate connections in compression “, Journal of Constructional steel Research 58(2002) 1143-1159.

\section{How to cite this article:}

Fathi M, Amiri H R, Rahimi H A, Exploring the cyclic loads conditions on behavior of modified connector plate of steel frame CBF. J. Fundam. Appl. Sci., 2016, 8(2S), 518-531. 